Revista Iberoamericana, Vol. LXX, Núms. 208-209, Julio-Diciembre 2004, 875-890

TRES REVISTAS LITERARIAS VENEZOLANAS DE LOS AÑOS SESENTA Y EL PROBLEMA DE LA CULTURA

\author{
POR \\ María del Carmen Porras \\ Universidad Simón Bolívar
}

El crítico venezolano Luis Barrera Linares ha concluido recientemente que un cierto afán de autonegación ha caracterizado a la literatura venezolana a lo largo de su historia. Aunque resulte paradójico, dice este autor, la necesidad de construir "una imagen que nos permita reconocernos como espacio literario en el conjunto de países latinoamericanos” (53) ha corrido pareja con la necesidad de cuestionar y poner en duda el valor de la propia producción intelectual nacional. Así, para este crítico,

\footnotetext{
la dicotomía regionalismo/universalismo, el apego al realismo, y la desatención de lo fantástico, la negación recurrente del peso específico de la obras, el aislamiento nacional y la escasa necesidad de trascender las fronteras patrias, aparte del desinterés notorio de la relación de los textos con sus destinatarios. (52, énfasis mío)
}

son los principales puntos de análisis que conforman, en general, la agenda de intelectuales y escritores venezolanos cuando piensan sobre la literatura de su país.

A riesgo de convertir estas páginas en una prueba que confirme el planteamiento de Barrera Linares, cuya validez no discutiremos aquí, pienso que aún no se ha reflexionado lo suficiente en Venezuela sobre esos tres problemas que he destacado en la cita anterior. Y creo que la insuficiencia parte de que la mayoría de las veces dichos problemas han sido planteados de forma aislada, sin relación unos con otros, lo que ciertamente no ha resultado productivo. Si detallamos el fragmento de Barrera Linares, notamos que no se establece entre los puntos que menciona ningún tipo de jerarquización ni articulación: ¿tienen todos el mismo peso o valor?, ¿podemos deslindar, por ejemplo, "la dicotomía regionalismo/universalismo" de "el aislamiento nacional?” y éstos de "la escasa necesidad de trascender las fronteras?” ¿No será, más bien, que si se acepta que los venezolanos hemos ido construyendo una cierta identidad literaria a base de cuestionamientos y negaciones, debemos poner en relación esos cuestionamientos y negaciones para lograr -o al menos hacer el intento de- comprender por qué nos cuestionamos de esta manera, por qué es que nos percibimos como nos percibimos?

En este sentido, creo que sería pertinente preguntar si no tendrá algo que ver el perpetuo lamento acerca de lo poco reconocida que es la literatura venezolana en el exterior con la queja constante sobre lo localistas de nuestros escritores -con contadas excepciones. Creo que sería pertinente preguntar si no será que esa concepción dicotómica 
con la que al parecer percibimos la relación entre un espacio que nos pertenece (nacional) y uno que nos sería ajeno (universal) nos impide ver que ese afuera que no es Venezuela puede y quizás debería comprenderse a partir de categorías que dieran cuenta de su complejidad y que, por lo mismo, permitiera establecer las conexiones necesarias entre el proceso cultural nacional y el de otros espacios, tanto nacionales (otros países de América Latina, por ejemplo), o supranacionales (la propia América Latina). Creo, así, que hay que preguntarse si la dicotomía nacionalismo/universalismo ha sido la causa de que en muchas ocasiones el debate en torno a la cultura y la literatura venezolana se mantenga dentro de los estrechos límites que esta construcción establece. Y también creo que habría que pensar por qué, aun generaciones intelectuales que hacen explícito su deseo de ruptura y cambio con respecto al discurso establecido sobre la cultura nacional no rompen esta dicotomía y, más bien, la mantienen en sus reflexiones.

Un caso que nos parece importante destacar en este sentido, es el de la generación de los años sesenta, conocida en Venezuela como "la izquierda cultural”. El derrocamiento de una dictadura militar de derecha en 1958 había determinado el inicio en el país de un período democrático que se auguraba -por primera vez en toda la historia de vida republicana- como medianamente duradero. Los jóvenes escritores e intelectuales que prácticamente ${ }^{1}$ estaban empezando a tomar parte activa en la vida nacional durante esta década encontraron en la estructura del grupo literario un medio por el cual hacer sentir una voz de disidencia en un ambiente cultural que sentían dominado por la institucionalidad. Los sesenta son, por ello, los años por excelencia de los grupos literarios en Venezuela y, sobre todo, de sus revistas, pues la publicación periódica fue considerada por la izquierda cultural como un efectivo instrumento de comunicación, que permitía establecer y participar en discusiones del momento y, más importante aún, provocar el diálogo y la polémica.

Sardio (1958-1961), Tabla Redonda (1959-1965), y Rayado sobre el techo (19611964), las dos primeras, revistas de grupos literarios homónimos y la última vocera de "El techo de la ballena”, son las tres principales publicaciones periódicas de estos años. Las tres aparecen en Caracas y entre sus redactores y colaboradores se encuentran los nombres de quienes durante varias décadas han constituido el establishment cultural nacional; así, entre los integrantes del grupo "Sardio" (1955-1961) tenemos a Guillermo Sucre (1933), Ramón Palomares (1935), Elisa Lerner (1932), Salvador Garmendia (1928-2001) y Adriano González León (1931); los dos últimos serán miembros también de "El techo de la ballena” (1961-1968) junto con Carlos Contramaestre (1933-1996), Caupolicán Ovalles (1936-2001), Edmundo Aray (1936) y Juan Calzadilla (1931); finalmente Manuel Caballero (1932), Rafael Cadenas (1932), Arnaldo Acosta Bello (1927) y Jesús Sanoja Hernández (1930) componen el comité editorial de “Tabla Redonda” (1959-1965).

La relevancia, pues, de estas publicaciones en la construcción de ese "rostro propio [...] imagen que nos permita reconocernos como espacio literario en el conjunto de países

\footnotetext{
${ }^{1}$ Decimos prácticamente, pues algunos de ellos habían comenzado su labor en el campo de la política, la literatura y el arte durante la dictadura de Marcos Pérez Jiménez. Guillermo Sucre y Jesús Sanoja Hernández, por ejemplo, habían participado en Cantaclaro, revista del grupo homónimo, de escasa duración -una sola entrega- publicada en 1950.
} 
latinoamericanos” (Barrera Linares 53), es evidente. No afirmamos que es en ellas que nace o se origina esa idea con respecto al aislamiento nacional, o se origina la dicotomía nacionalismo-universalismo para comprender las relaciones entre la cultura venezolana y las de otros espacios, pero vamos a tratar de analizar cómo la afrontan, cómo trabajan estos grupos con esas ideas.

\section{I. ¿'TRES REVISTAS, TRES DISCURSOS?}

Desde hace ya varios años, la sentencia de Mariano Picón-Salas sobre el tardío comienzo del siglo xx en Venezuela ha sido matizada por la crítica. ${ }^{2}$ Sin embargo, la idea del retraso cultural venezolano sigue siendo aceptada y para muchos, tal retraso debería extenderse hasta 1958, pues es en este año, como decíamos antes, que el país entra en un período republicano y democrático, relativamente estable, que permitiría la suficiente libertad y seguridad al intelectual, al escritor, al artista plástico para realizar su trabajo sin temor a represalias políticas. Así, al trabajar sobre la revista Sardio, una especialista afirma con respecto al contexto cultural en que ésta surge:

Por su situación política particular, Venezuela presentaba un cierto desfase con relación a los demás países del continente. Los regímenes caudillescos o dictatoriales que la habían oprimido desde su independencia habían obstaculizado el proceso intelectual, impidiendo un desarrollo cultural orgánico como el que se había dado en otras naciones latinoamericanas [...] Recién en ese año [1958], Venezuela nacía a la democracia y se abría a un amplio debate ideológico, tanto tiempo reprimido. El sentimiento de entrar en una nueva era, en ruptura total con el pasado, agitaba a la mayor parte de la población, deseosa de grandes cambios (Vandorpe 78, énfasis mío).

¿Cómo reciben esta idea del retraso cultural nacional y se construyen como generación ante ella los intelectuales y escritores venezolanos de los sesenta? La respuesta no es del todo simple, aunque desde un comienzo en este trabajo hemos afirmado que esta generación no resulta, en este sentido, tan cuestionadora como se esperaría de un movimiento cultural surgido en esa década.

Así, una revisión detallada de Sardio, Tabla Redonda y Rayado sobre el techo daría cuenta de cómo los puntos de contacto y de distanciamiento entre las propuestas estéticas e ideológicas de cada grupo se articulan, en ocasiones, de forma contradictoria, de manera tal que no siempre resulta fácil señalar con precisión las tendencias afines y las diferencias que mantenían entre ellos.

Sardio, primera revista que aparece cronológicamente, está afiliada al proyecto político socialdemócrata (representado por el partido Acción Democrática) que va a

\footnotetext{
${ }^{2}$ En 1935 muere Juan Vicente Gómez, quien había gobernado al país desde 1908. Nelson Osorio afirma que la expresión de Mariano Picón Salas "es una de esas frases que en cierto modo más que de la realidad a la que apunta, dice de la perspectiva desde la cual se esta mirando la realidad. Para toda una falange de intelectuales que vivieron su período de formación y adolescencia durante la dictadura de Juan Vicente Gómez, se hacía necesario denunciar las ominosas condiciones de castrados aislamiento que un régimen oprobioso hizo vivir al país” (17).
} 
dominar en el país una vez ganadas las elecciones realizadas a finales de 1958. Tabla Redonda, que surge poco después de ella, se presenta como la respuesta que, en el plano de lo cultural, lanza la izquierda más radical, específicamente, el Partido Comunista. Por su parte, Rayado sobre el techo resulta una escisión de Sardio, escisión que hacen pública en 1961 aquellos escritores e intelectuales que sentirán la necesidad de corresponder en el medio literario y artístico con el movimiento de guerrillas que surge en el país por entonces. Estas diferencias en la afiliación política son importantes para comprender las ciertas tensiones que caracterizarán más de una vez el debate cultural entre los grupos, aunque en el fondo no signifiquen profundas diferencias teóricas entre ellos; por ejemplo, el problema del compromiso del intelectual, propio de esos años, provocará un continuo enfrentamiento entre los grupos, y en diversas ocasiones cada uno fijará su posición frente a la de los demás, intentando marcar la particularidad de su propuesta. En realidad, una lectura de manifiestos y artículos con respecto a este tema muestra que el asunto del compromiso era tratado de forma semejante por todos: así, los integrantes de Sardio -supuestamente críticos (aunque no opositores) de la idea del compromiso- se muestran tan irreductibles en su defensa de los postulados reformistas de la democracia naciente como los de Rayado sobre el techo en su apoyo a las ideas revolucionarias de las guerrillas -supuestamente paradigmas del compromiso.

Entonces, volviendo al problema del retraso cultural, deberíamos afirmar que, pese al afán de independencia y distancia con que cada grupo se presenta frente a los otros, pese a sus posturas políticas, todos ellos siguen, más apegados unos, más críticos y cuestionadores otros, el camino de una modernización y puesta al día de la cultura nacional que desde su primer manifiesto esbozan los integrantes de Sardio y que tiene como base la ya mencionada dicotomía nacionalismo-universalismo.

\section{LA MODERNIZACIÓN VIOLENTA DE SARDIO}

Así califica Ángel Rama, uno de los primeros en trabajar sobre el proceso políticocultural venezolano de los años sesenta, el proyecto que representa Sardio. El término parece adecuado pues una revisión de los índices de las seis entregas que componen la colección (dos de ellas números dobles) ${ }^{3}$ da cuenta de cómo en sus páginas se reúnen, en una suerte de compilación antológica dirigida a un lector poco informado o escasamente conocedor de las tendencias literarias mundiales desde comienzos de siglo, textos de y sobre las vanguardias literarias europeas, relatos de autores norteamericanos y europeos de la posguerra, así como reseñas sobre cine y música que comentan propuestas consideradas novedosas para el ambiente cultural venezolano. En este sentido, uno de los principios

\footnotetext{
${ }^{3}$ En realidad esta revisión no incluye la última entrega de la publicación, el № 8, que aparece en 1961. Este número constituye, desde nuestro punto de vista, no el último de la colección de Sardio, sino la presentación oficial del grupo "El techo de la ballena". Varios indicios apunta hacia esta lectura: a lo largo de toda la colección, la revista Sardio había seguido una numeración de página continua que se rompe en esta ocasión; cambia el diseño de portada y de página; del comité de redacción original, sólo se mantiene un nombre y en la lista de colaboradores aparecen la totalidad de los integrantes del nuevo grupo, quienes aprovechan y publican en esta entrega sus primeros manifiestos.
} 
fundamentales del grupo: "asumir una actitud crítica y orientadora en medio de la vertiginosa dinámica de recuperación que es actualmente la patria” (Anónimo “Testimonio" 1), expresado en el primero de sus “Testimonios”, nombre general que los sardianos dan a sus manifiestos y que utilizarán a lo largo de sus entregas como textos programáticos, se intentará cumplir a través de una puesta al día que quiere ser al mismo tiempo inmediata y efectiva: "se nos hace evidente que el exceso de color local, con todas sus derivantes [sic], ha viciado de raíz gran parte de nuestras manifestaciones artísticas [...] Debemos alimentar una firme voluntad de estilo, una vigilante dedicación al estudio y una ideología más original y moderna” (3).

Rama lo entiende así y al hacer una enumeración de algunos de los autores y temas que encontramos en las páginas de Sardio, nos explica el por qué de esta selección:

[Para los sardianos] Como el primer paso consistía ponerse al día, romper con el pasado insertando corrientes universalistas que lo cancelaran bruscamente, y como al mismo tiempo su formación cultural todavía se hizo en la órbita de la influencia francesa con muy escasos atisbos de la aportación renovadora norteamericana se remontaron a las vanguardias de la primera posguerra en París: es el largo estudio sobre Dadá, de Georges RibbemontDessaignes que traducen, es la incorporación al español de textos de Antonin Artaud o de Tristan Tzara; luego, de la segunda posguerra, también francesa: Adamov, Samuel Beckett, etc. Tardíamente aparecerán Thomas Wolfe o Dylan Thomas, asimilados por su impetuoso frenesí. (Rama, "Salvador Garmendia” 105) ${ }^{4}$

El índice de Sardio nos habla, por ello, de cómo los integrantes de este grupo percibían al país y su cultura: provinciana, aislada y atrasada. Tal percepción se reafirma en sus manifiestos; de esta manera, leemos en el primero de ellos: "Nuestra cultura parece ayuna de ideas y problemas, como si aún viviéramos en una Arcadia de imperturbables regocijos. Hay que poner de relieve una conciencia más dramática de la realidad y del hombre” (Anónimo “Testimonio”, 3) y, con una expresión más radical, en el segundo:

Que las pasadas generaciones como tales y no como tránsito en ellas de grandes individualidades, abandonaron el mundo de nuestra cultura a un dudoso juego de intereses personales, de caprichos y de mistificaciones y que no supieron recrear a plenitud la avasallante y siempre desasosegada realidad de nuestra existencia, lo viene a mostrar el mismo desarrollo de la vida venezolana en todas sus manifestaciones [...] Antes que seres requeridos por una vocación o por las determinantes de la inteligencia, hemos tenido a todo lo largo de nuestra cultura pequeños aprendices de 'mandarines' [...] Con una irresistible seducción por el prestigio superficial o por una gloria aldeana, se embriagaron con elogios mutuos y acomodativos [sic], hasta el punto de que hicieron arte e institución de esa despreciable y ya proverbial “política literaria”. (Anónimo “Constantes” 279)

\footnotetext{
${ }^{4}$ Si revisamos más detenidamente no sólo encontraremos estos textos que señala Rama. También podremos hallar un ensayo sobre Albert Camus ( $\left.\mathrm{N}^{\circ} 1\right)$, una reseña sobre la escritora Carson McCullers ( $\left.\mathrm{N}^{\circ} 2\right)$, un ensayo de Claude Roy sobre André Malraux ( $\left.\mathrm{N}^{\circ} 2\right)$, una nota sobre Federico Dürrenmatt, otra sobre John Osborne (ambas en el $\mathrm{N}^{\circ} 5-6$ ), y la reproducción parcial de una entrevista a Jean-Paul Sartre tomada del semanario L'Express $\left(\mathrm{N}^{\circ} 7\right)$.
} 
Para Rama, a pesar de que "hubo deformación, tristemente frivolona a veces, del afán de modernización [en Sardio], respondía éste sin embargo, a una exigencia real y auténtica del momento" ("Salvador Garmendia” 104). De allí que considere bastante fiel el retrato que en la publicación se llevó a cabo de la realidad cultural venezolana: “[...] debe reconocerse la imperiosa necesidad de élites rigurosas que tenía la cultura venezolana, no para educar a las masas solamente, sino para modernizar al país y ponerlo al día” (104), afirma, y añade con respecto a la literatura: "Las remanencias folklóricas resultaban agobiantes, así como la literatura moralizadora a la que sigue adherida una clase burguesa [...] el agobiante modelo de Rómulo Gallegos o Andrés Eloy Blanco [...] válidos en su tiempo y respetables en su honrada invención artística, ya no servían a los jóvenes creadores" (104). Sin embargo, es curioso, en este sentido, que Rama considere como "distingo correcto" el que Sardio planteara que " "No confundimos universalidad con cosmopolitismo"” (Anónimo “Testimonio” 1) y no analice con mayor detenimiento de qué forma la expresión de sus manifiestos, sus artículos, y hasta sus reseñas, negaban esta afirmación y esta distinción que él encuentra tan clara. Lo que Sardio identifica con universal es, por supuesto, lo occidental, entendido como una categoría atemporal, fija en el tiempo. Por ello, el retrato que se ofrece de la cultura nacional, está cruzado y marcado por ella.

De allí que para los sardianos, la educación sea asumida como un medio por el cual "[incorporar] a nuestro pueblo al goce profundo de los grandes valores del espíritu" (Anónimo “Testimonio” 2). Los sectores populares, por tanto, desde la perspectiva de Sardio, parecerían carecer de valores culturales; sin embargo, lo que quieren resaltar los sardianos no es que el pueblo carezca de dichos valores - "Respetamos en el folklore y en nuestras mejores tradiciones el alma esclarecida del pueblo [...]” (3)- sino que ellos, en el estado en que se encontraban, no eran suficientes para insertarse a lo universal: "Para asumir la gravedad de nuestro destino histórico requerimos la presencia de un pueblo luminoso y creador, sensible al imperio de las ideas y de la verdad” (2).

Notemos cómo, desde este primer manifiesto, y a lo largo de su colección, es marcada la tendencia de Sardio a preferir hablar “del hombre”, “de la patria”, en general y un tanto grandilocuentemente que a expresar sus propuestas con respecto a la cultura nacional de manera más directa y concreta. Si su segundo manifiesto comienza con la siguiente afirmación: “Acaso esta nueva entrega requiera una definición más radical y exigente de nuestra revista; pero no una altisonante y pretenciosa formulación de principios” (Anónimo “Constantes” 227), tal propósito parece perderse unas líneas más abajo:

constituimos una generación consciente de su destino, poseída por una voluntad de trascendencia, fiel a las verdaderas y dramáticas constantes del tiempo que le ha tocado vivir y en él enraizada y comprometida, dispuesta a redimir por ejercicio del espíritu y de la verdad lo que otras generaciones parecen haber sacrificado por negligencia y las pequeñas ambiciones; que somos un grupo de escritores y artistas para quienes la creación es combate con el destino o con la historia y no esa farsa creciente que es la cultura de nuestro país. (277-78)

Esta forma de enunciar sus postulados está estrechamente vinculada con la perspectiva desde la que veían al país - desde afuera y desde arriba- y con el proyecto de futuro que planteaban: 
El hombre de hoy está volcado hacia una experiencia más vasta y compleja, que sería inútil simplificar con limitaciones regionales o partidistas, y está urgido por anhelos profundos de universalidad. Orientados hacia esa gran experiencia es como debemos tratar los problemas nacionales. Es imperioso elevar a perspectivas más universales los alucinantes temas de nuestra tierra. (Anónimo “Testimonio” 3, énfasis mío)

La oposición entre lo regional y lo universal afianza aquí la percepción dicotómica entre lo nacional y lo universal. Efectivamente, la incompatibilidad entre los dos primeros términos marca cómo lo universal es percibido como totalidad sin fracturas internas, sin divisiones, sin regiones. Y cómo lo nacional, que se siente no es así, se trata de leerse de la misma manera. Formuladas como categorías idealmente equivalentes, lo nacional (como totalidad) y lo universal (como otra totalidad) darían cuenta de una división espacial simple y dicotómica que negaría cualquier otro espacio alternativo de pertenencia y articulación.

La presencia en la revista de autores como Alejo Carpentier, Miguel Ángel Asturias o Gonzalo Rojas, presencia que los propios sardianos destacan en su segundo manifiesto, no está relacionada con una percepción de América Latina como un espacio cultural alternativo. Así, en una reseña que Guillermo Sucre realiza sobre Guerra del tiempo, advierte el autor que "Hombre de dos culturas, hombre de encrucijadas y de conciencia dramática [...] Alejo Carpentier ha sabido trascender la exigua y no menos anacrónica problemática de nuestra literatura y crear una vasta secuencia de temas que satisfacen los más inflexibles requerimientos de universalidad” (164). No se nos escapa que Sucre habla de "nuestra literatura", relacionándose con Carpentier, pero tal relación tiene, como en el caso del regional referido a lo nacional, sentido de límite, de barrera, tiene un sentido peyorativo; por eso, lo que se valora de la producción de Carpentier es su capacidad para trascender dicha limitación. Planteamientos muy semejantes se harán con respecto a la narrativa de otros autores, como la de Juan Rulfo.

\section{LA TOMA DE POSICIÓN DE TABLA REDONDA}

En cierta forma, lo que afirma Rafael Cadenas desde una entrevista en Tabla Redonda con respecto a la poesía nacional puede aplicarse a la retórica de los manifiestos de Sardio:

Siento [que] le falta frescura, desnudez, audacia. Tenemos miedo a llamar las cosas por
su nombre, miedo a las palabras, miedo a decir lo que sentimos, miedo a la claridad, al
claroscuro y la oscuridad, miedo a apartar prejuicios, miedo a ser nosotros mismos, miedo
a que sea social o individual, miedo a que se desmande, miedo a que no guste, miedo a
que penetre las grutas del ser, miedo a la elocuencia, miedo a todo lo que pueda nutrirla. (2)

Interesa sobre todo destacar la última palabra de las declaraciones de Cadenas: nutrir. Y es que lo que más necesitaba ser nutrido durante esta época era justamente el debate sobre la cultura nacional y sus problemas. Quienes escriben en Tabla Redonda consideran que es esto lo que hacían al publicar su revista. Y, por ello, a manera de crítica, este grupo será parco a la hora de establecer posiciones de conjunto, y preferirá la opción de los 
artículos individuales. Así, no es sino en la cuarta entrega de la revista que publican un texto titulado "Nuestras credenciales”, que podría considerarse como un manifiesto, aunque esté firmado sólo por Arnaldo Acosta Bello. Un fragmento nos muestra ese otro estilo retórico que los de Tabla Redonda presentarán frente al de Sardio:

Existe (siempre ha sido así) la posibilidad de que una generación joven se enfrente con sentido crítico, de examen de análisis, a otro de curso casi andado y cuya actitud suele ser en esta hora, la de inventario, la de resumen [...] Los jóvenes no rechazamos tal herencia, conscientes como estamos de que con ella podría elaborarse un pensamiento más tradicional, tomando esta palabra, desde luego, como algo que concede un sentido de solidez, de estructuración por un proceso de rupturas y acomodamientos y no como simples ensambles y eslabonamientos, que no constituirían otra cosa sino un crecimiento por yustaposición [sic] y una pérdida de criterio. (4)

La actitud de los integrantes de Tabla Redonda con respecto al retraso cultural nacional y la dicotomía nacionalismo/universalismo quiere ser diferente que la de Sardio y hasta cierto punto lo fue. Rama afirma que los integrantes de este grupo

procedentes de una militancia partidista de izquierda y con una formación teórica más desarrollada, renovaron las tesis de la responsabilidad del intelectual peculiares del comunismo, poniendo en evidencia el fenómeno que escapaba a Sardio: la lucha de clases [...] Los "sardianos" se circunscribían a sus orígenes medioburgueses, a su rebeldía de tipo individualista y a su devorante preocupación por los niveles de capacitación intelectual y artística. (“Salvador Garmendia” 103-104)

Rama aquí parece darle demasiada importancia (o única importancia) a las diferencias ideológicas entre los grupos, que, por supuesto, hay que señalar. Ahora bien, si tomar en cuenta la lucha de clases quiere decir que desde Tabla Redonda se trató de reflexionar de manera más directa y concreta (quizás ésta última sea la palabra clave) sobre el país, si se trata de que Tabla Redonda presenta una agenda más realista con respecto a la problemática de la cultura, pues el planteamiento de Rama resulta acertado. En este sentido, si revisamos el índice de Tabla Redonda, ciertamente no tendremos esa imagen antológica característica de Sardio: más artículos que textos narrativos o poéticos; más crítica, diálogo y polémica con el entorno cultural nacional. ${ }^{5}$

La polémica, hay que reconocerlo, se centró en Sardio. De hecho, el primer número de Tabla Redonda abre con un artículo crítico de Arnaldo Acosta Bello que responde a un comentario un tanto negativo sobre Pablo Neruda que Guillermo Sucre había publicado en Sardio. En el segundo número, Jesús Sanoja Hernández y Acosta Bello contestan la réplica que Sucre escribe en un suplemento literario de El Nacional, periódico caraqueño de circulación nacional. Esta polémica, con ser una de las más conocidas de entonces, interesa no tanto por el problema en sí que se discute (el valor de la poesía "más

\footnotetext{
${ }^{5}$ La definición que de ella ofrece Guillermo Sucre a raíz de la publicación de su primer número hace evidente la distancia entre Sardio y Tabla; así, Sucre la denomina "suerte de gaceta literaria, polémica y decidida en sus planteamientos" ("Sobre Tabla Redonda” 3).
} 
comprometida” de Neruda) sino porque señala la posición que los integrantes de Tabla Redonda escogerán -o se verán obligados a hacerlo- para participar en el debate cultural de entonces. Sanoja Hernández nos lo muestra claramente en su contestación a Sucre: tras cuestionar la debilidad conceptual del artículo, el autor apunta hacia la perspectiva de análisis que él considera más productiva:

$\mathrm{Al}$ arte lo juzgamos más que como un club de magnates, más que como un monopolio contra el cual nada o poco se hace en el terreno creador, como una actividad donde hay obra, tendencia, crisis, doctrina, clase social, actitud generacional, defensa y ofensa políticas, genio, pobreza, servicio y servidumbre” y como conclusión afirma: “es la trinidad de posibilidades que presento a Guillermo Sucre -que 'Tabla Redonda' presenta a 'Sardio'-, en espera de que el diálogo florezca y produzca y de que no se reduzca una vez más al monólogo que tras de sí ha arrastrado cada generación o cada prestigio intelectual ("Notas" 2).

Presentar una respuesta a Sardio, ofrecer opciones para el diálogo y esperar que éste acontezca: éste será el papel de Tabla Redonda. Es, en gran medida, un papel secundario, como si el hecho de haber aparecido meses antes los limitara a una constante posición de contestación y cuestionamiento de Sardio.

En ese sentido, las precisiones que Tabla Redonda hacía eran necesarias y acertadas, pues señalaban las ambigüedades y vacíos de un discurso sobre la cultura que, como hemos afirmado antes, parecía abstraerse de su entorno concreto:

La crítica oficial en Venezuela asume posiciones generales. Se declara valiente cuando acomete fenómenos vagos e imprecisos, posiblemente válidos para Escandinavia o Siam tanto como para nuestro país, pero es en sumo grado elusiva y huidiza cuando trata de bajar la abstracción al reino de lo concreto. (Sanoja Hernández “Loa y destrucción” 3)

Por ello, a los de Tabla Redonda no se les escapará la presencia de la dicotomía nacionalismo-universalismo en el debate cultural nacional y el empobrecimiento que dicha estructura estaba causando.

A comienzos de 1960, se genera una polémica en torno a la novelística venezolana. Una entrevista realizada a Salvador Garmendia, donde se daba por sentado que los jóvenes autores nacionales se sentían más identificados con la figura y la escritura de Kafka que con las de Gallegos, Miguel Otero Silva o Mariano Picón Salas, provoca diversas reacciones en la intelectualidad de entonces. ${ }^{6}$ Tabla Redonda interviene ya al final de la polémica intentando realizar un balance de ella, a través de un artículo de Jesús Sanoja Hernández. Como ya hemos señalado será costumbre en la publicación, este texto es, ante todo, una respuesta a las ideas que aporta Adriano González León, por entonces, como Salvador Garmendia, integrante de Sardio. Su título es simplemente "Novela” y desde nuestra perspectiva debe considerarse uno de los más importantes de esta publicación -y quizás, entre los mejores que se presentan en las revistas de esta época.

${ }^{6}$ Parte de esta polémica puede leerse en: Juan Liscano. Tiempo desandado. 
Para Sanoja Hernández, la posición asumida por González León se caracterizaba por su extremismo: su repudio a los valores de la narrativa criollista se percibía tan exagerado y simplificador como su exaltación de la obra de Kafka. La estrategia principal utilizada por González León,

Escoge formas puras, cristalizadas, moldes en que no palpita el movimiento histórico, para arremeter contra los más deleznables, desde luego opuestos a los que él busca impulsar. Así, por un lado, tendríamos: aldeanismo, etiqueta folklórica, manifiesto político y venezolanidad prefabricada como adherencias al hecho narrativo; por el otro: la fuerza renovadora de las técnicas modernas (Joyce, Kafka, Faulkner), que constituirían la tabla salvadora del naufragio en que nos debatimos desde Gallegos. (3)

daría cuenta de cómo este autor, "manejando, pues, verdades evidentes, como el estancamiento más o menos general a partir de Gallegos y la falta de un enfoque creador diferente, $[\ldots]$ nos pone en el disparadero de elegir una u otra cosa, aunque previamente nos haya orientado hacia la suya” (3). Sanoja Hernández descubre el funcionamiento de la dicotomía nacionalismo-universalismo que compara con otras:

revela sagacidad oponer términos como apolíneo y faústico, reducir estilos a clásicos y románticos, pedir arte urbano una vez que el rural caduca, hablar de comunicación cuando el hermetismo ahoga, sostener behaviorismo al momento en que la instrospección quiebra, abrazar el realismo si el abstraccionismo no rinde, hacer esto o lo otro aunque siempre apoyándose en antagonismos de contrarios [...] revela sagacidad, pero no es, a mi modo de ver, un signo de lealtad ante los problemas reales que necesitan un examen interno más profundo, menos mecánico. (3)

Ante este panorama, la propuesta de Sanoja Hernández no se hace esperar: se trata de encontrar una vía alternativa; afirma entonces el autor que

\begin{abstract}
si actualmente en Venezuela se intenta introducir “otra forma de narrar” tendríamos primero que ponernos de acuerdo de dónde la vamos a sacar, si de una contemporaneidad al modo de Kafka y Joyce, como presumo es el deseo de muchos de los compañeros de "Sardio", si de un acomodamiento externo a la realidad geográfica y social [...] o si de una ansiosa exploración en la existencia, tanto íntima como externa, que vivimos, que nos rodea y nos llena. Creo que resulta fructífero añadir siquiera toscamente esta tercera posibilidad, pues de no hacerlo tendríamos que aceptar innecesariamente el tránsito violento que proponen [Adriano] González León y Salvador Garmendia, cual es el de romper con la muralla tradicionalista y acatar una "contemporaneidad" indefinida (3-4, énfasis mío)
\end{abstract}

Recordemos una cita anterior, en la que también Sanoja Hernández lanza una propuesta a Sardio, representada aquella vez por Guillermo Sucre. Igual que en esa ocasión, la alternativa frente a los planteamientos sardianos aparece simplemente esbozada; de esta manera, si buscamos un mayor desarrollo de la propuesta en el texto, no lo encontraremos, lamentablemente. Encontraremos aproximaciones a lo que necesita la novelística nacional: "la búsqueda de la realidad, [...] los sucesos comunes y la agitación social, la historia y el fenómeno circundante” (4), "Y si queremos transformar el lenguaje 
aldeano y la sensiblería patriotera para buscar una nueva narrativa, ¿no tomaremos en cuenta el mundo, la realidad novelística tal como se presenta, el sistema de la contemporaneidad?” (4 destacado en el original), pero no mucho más. De hecho, la conclusión de este artículo no se corresponde con el nivel de discusión con que se venía desarrollando el mismo: “Tal vez por eso urge mayor reflexión, una mejor disciplina, más conciencia. Como fuera, la circunstancia de que discuta ahora sobre novelística [...] es hoy motivo de aliento" (5).

De esta manera, marginados, más que nada por ellos mismos, a una posición secundaria con respecto a Sardio, los integrantes de Tabla Redonda en realidad no lograrán articular propuestas que constituyan opciones diferentes, de cambio, frente al discurso modernizador de Sardio.

\section{LA RADICALIDAD UTÓPICA DE “EL TECHO DE LA BALLENA”}

Una exposición de arte y la publicación de su primer manifiesto en el diario caraqueño La Esfera anuncian la aparición en 1961 de "El techo de la ballena”. Rayado sobre el techo de la ballena es el nombre de la plaquette con que este grupo, en el que mejor se articulan en la década escritores y artistas plásticos, acompaña esa exposición. Bajo ese título, un poco más corto -exactamente, Rayado sobre el techo- los balleneros presentarán una plaquette más en 1963 y en 1964, una publicación de casi 70 páginas, compuesta por textos y fotografías de distintas exposiciones realizadas por el grupo durante esos tres años de vida. Éste será el tercero y último número de Rayado sobre el techo, lo que marca el inicio del proceso de desaparición del grupo, que será largo pues sucederá en 1968.

Desde sus primeros textos, los balleneros se preocuparán por expresar de manera vehemente su deseo de ruptura con respecto al medio cultural nacional:

No como producto del azar, ni como ocio o actividad de un grupo de intelectuales evadidos o presuntamente inadaptados en el actual engranaje social, sino más bien como un gesto de franca protesta ante la permanente e indeclinable farsa cultural del país y el continuado desacierto político y económico que registra la democracia venezolana, el Techo de la Ballena ha comenzado a poner en evidencia la inveterada mediocridad de nuestro ambiente cultural. (Anónimo "Homenaje a la cursilería” 136)

Las estrategias para llevar a cabo eso que señalan en el fragmento citado serán varias y, algunas de ellas, únicas del grupo durante la década; por ejemplo, el humor, que se encuentra presente en la mayor parte de las publicaciones, exposiciones y actos del grupo. Ellos mismos así lo reconocen cuando se sienten obligados a señalar que "no queremos proclamarnos sacerdotes del absurdo y menos aún de la burla, categorías que todos ya hemos superado. El absurdo y la burla serán tan sólo medios de expresión y nada más”. (Anónimo "Pre-manifiesto" 136).

Quizás más sinceros o más directos que los sardianos, los balleneros reconocen su deuda con las vanguardias europeas: "pareciera que todo intento de renovación, más bien de búsqueda o de experimentación, en el arte, tendiera, quiérase o no, a la mención de grupos que prosperaron a comienzos de este siglo, tales Dadá o el Surrealismo” (3), aunque enseguida maticen tal filiación: 
Si bien es cierto que tenemos muy en cuenta esas experiencias, al fundar el Techo de la Ballena, no pretendemos revivir actos ni resucitar gestos a los que el tiempo ha colocado en el justo sitio que les corresponde en la historia [...] No pretendemos situarnos bajo ningún signo protector; queremos, eso sí, insuflar vitalidad al plácido ambiente de lo que se llama cultura nacional. (136)

Es ya un lugar común hacer alusión a la radicalidad con que este grupo asumió tal tarea y la conmoción que en ocasiones causó: una exposición como el "Homenaje a la necrofilia”, donde fueron exhibidos, entre otras cosas, cuerpos de reses sacrificadas, escandalizó al país en 1962 y ese mismo año la publicación en las ediciones del grupo del libro de Caupolicán Ovalles, ¿Duerme usted, señor presidente?, largo poema especialmente crítico y duro contra Rómulo Betancourt obligó a su autor a abandonar el país debido a las represalias del gobierno, de las que no escapó su prologuista, González León, quien fue detenido. En ese sentido, Rama asegura que "El Techo de la Ballena propuso una revisión drástica de los valores culturales vigentes y una transmutación de la literatura y el arte que se ejercían en el país, todo ello al servicio de un proyecto militante, contemporáneo, de apoyo a la insurgencia revolucionaria” (Rama, "Salvador Garmendia” 122). La afiliación política que señala Rama es fundamental: como los mismos balleneros lo expresarán en su segundo manifiesto:

Nuestras respuestas y nuestras acciones surgen de la misma naturaleza de las cosas y de los acontecimientos, como claro ejercicio de la libertad, clave para la transformación de la vida y la sociedad [...] Como los hombres que a esta hora se juegan a fusilazo limpio su destino en la Sierra, nosotros insistimos en jugarnos nuestra existencia de escritores y artistas a coletazos y mordiscos. (Anónimo “Segundo manifiesto”)

Desde la perspectiva de Rama, este hecho distinguiría a los balleneros de otras agrupaciones del continente:

Si [los balleneros] fueron menos cultos que los escritores de la "mafia” mexicana [...] o que los "jefes" de la poesía concreta de Sao Paulo [...] y por consiguiente su esfuerzo de modernización se situó preferentemente en la adopción de la contribuciones ya consolidadas del surrealismo francés, con el agregado del descubrimiento de la poesía beatnik norteamericana [...] en cambio fueron capaces de un planteo político y social [...] de un esfuerzo sistemático para integrar los distintos orbes de la vida humana -social, político, estético, vital- en un solo movimiento urgido. (Rama, “Salvador Garmendia” 123)

Más apegados a la realidad y a la acción que los sardianos y más decididos en sus propuestas que los integrantes de Tabla Redonda, los balleneros parecieran haber superado las limitaciones de esos dos grupos anteriores. Hay que reconocer sin embargo que de su herencia sardiana les quedó la afición por el manifiesto y los textos programáticos, como también su estrecha vinculación con las literaturas europeas y norteamericanas. ¿Encontraron ellos la posición alternativa a la dicotomía universalismo-nacionalismo?

Al menos, son los que más se acercan. De esta manera, González León diferencia, en el mundo externo a Venezuela, un espacio con el que, considera, el país tiene particulares conexiones de pertenencia: 


\begin{abstract}
De este soplo perturbador, introducido en un medio beato y conformista, de no haber otras realizaciones, EL TECHO DE LA BALLENA extrae su orgullo vital. Y de allí parte una posibilidad aproximativa hacia un mundo más amplio como el de América Latina. Sometidos por igual al fraude, al robo y a la alienación, igualmente hostigados por los infantes de marina y las compañías petroleras o bananeras, en todos los países se cumple por igual un proceso de imbecilización y trampa a la cultura. (González León, “¿Por qué la ballena?" 3-4)
\end{abstract}

Quizás empujados por el momento histórico que vivieron y que determinó en gran medida su aparición como grupo y las actividades más importantes y recordadas, ${ }^{7}$ las guerrillas), los balleneros lograron eludirse de la discusión sobre el retraso de la cultura nacional y, por tanto, de la dicotomía nacionalismo-universalismo, pues se concentraron únicamente en el ambiente nacional y así descubrieron lo que éste les ofrecía para trabajar y que parecía haber sido despreciado hasta entonces: "las barriadas miserables, los basurales, la violencia legalizada, la brutalidad y la concupiscencia del poder” (Rama, “Salvador Garmendia” 137).

Por otro lado, y dadas las características y lo “productivo” de los “diálogos” entre Sardio y Tabla Redonda, los balleneros dejan de lado la discusión y plantean la necesidad de asumir la escritura y el arte como acción: “vivir es urgente / de ahí que la ballena para vivir no necesita saber de Zoología [...] pocas realidades son tan emocionantes como un hombre que rompe con todas las liturgias del lenguaje” (Anónimo “El gran magma”).

La discusión, pues, sobre las relaciones entre la cultura nacional y una supuesta cultura universal, les pareció superflua y así, a través del humor, se burlan de ella: “¿Por qué la ballena?, preguntó alguien [...] ¿ ¿por qué la ballena, elemento austral o boreal, y no un caimán, tan vivo y bien criadito en nuestros paraísos tropicales [...] porque hubiera sido fácil elegir el caimán. O porque hubiera sido de señoritos estetas elegir el hipocampo" (González León, “¿Por qué la ballena?” 3-4).

Sin embargo, y a pesar del tono irónico, la escogencia de la ballena como símbolo del grupo quizás pueda resultar una vía para comprender de qué manera, aunque sin hacer de ello tema de artículos o polémicas, los balleneros afrontaron las relaciones entre una cultura nacional y otra diferente, externa, ya sea universal o latinoamericana. Fue Carlos Contramaeste, el principal artista plástico del grupo quien había leído en Antiguas literaturas germánicas (1951) de Jorge Luis Borges una definición del mar que había llamado su atención: "techo de la ballena”. La decisión de colocar bajo este nombre al grupo quizás pueda considerarse producto del azar, pero si pensamos que para los balleneros, la consideración de la escritura y arte como acción es uno de sus lemas, es probable que ese gesto no sea gratuito. De esta manera, González León afirma en el texto de su autoría que hemos venido citando:

${ }^{7}$ Entre 1961 y 1963 el movimiento guerrillero venezolano realiza sus más sonadas acciones: en 1962, levantamientos militares en las ciudades de Carúpano (Estado Sucre) y Puerto Cabello (Estado Carabobo), conocidos como el “Carupanazo” y el "Porteñazo”, respectivamente, y en 1963 el asalto al Tren del Encanto en el Estado Aragua. 


\begin{abstract}
la ballena está en el medio de la bondad y el horror, sujeta a todas las solicitaciones del mundo y el cielo, con su vientre dignísimo que se ríe de Jonás y engulle un tanquero de petróleo, toda extendida de uno a otro extremo de la tierra, que casi es la tierra misma o es pájaro minúsculo que picotea su diente careado [sic] en el cual nadan los peces. Esa amplitud natatoria, ese deslizarse frenético [...] Ese empuje hacia lo desconocido que puede acrecentarnos la razón de vivir y contaminar los instrumentos de una substancia corrosiva que cambie la vida y transforme la sociedad. (González León, “¿Por qué la ballena?” 4)
\end{abstract}

La ballena es la totalidad: es aquello que desborda fronteras, que cruza territorios, que avanza en el mar, al fin de cuentas, más fácil de atravesar que la tierra. La modernización propuesta por Sardio distinguía cultura nacional de cultura universal; quienes escribían en Tabla Redonda avistaron, pero no definieron, un territorio alternativo que rompiera con tal dicotomía; los balleneros sueñan con un espacio donde lo nacional, lo latinoamericano, lo universal se entremezclen. ¿ ¿Fue suficiente el sueño? Ciertamente que no. Los balleneros marcaron sus acciones con un fuerte tinte de utopía, lo que habla de cómo ellos mismos percibían la cierta irrealidad de sus propuestas. De esta manera, la herencia idealista de los sardianos pesaba en ellos más de lo que se atrevían a admitir.

\title{
V. A MODO DE CONCLUSIÓN
}

La escritora venezolana Ana Teresa Torres (1945), quien ha recibido diversos reconocimientos nacionales e internacionales por sus novelas, ${ }^{8} \mathrm{y}$ es considerada una de las mejores escritoras de la literatura venezolana actual afirmó no hace mucho:

En términos generales, Venezuela es un país bastante aislado del circuito literario internacional, no sólo en cuanto a los centros hegemónicos sino incluso con respecto a los otros países latinoamericanos. En la segunda mitad de los años ochenta y principios de los noventa, paradójicamente cuando los recursos económicos del Estado iban en disminución, tuvo lugar el esbozo de una política de promoción exterior de la literatura, y se hicieron algunos intentos de vinculación, tales como coloquios, simposiums, viajes de escritores a las ferias internacionales, presencia de nuestras editoriales en las ferias, etc., planes que por distintas razones no culminaron en un proyecto de expansión cultural. En definitiva [...] nuestra literatura es prácticamente desconocida en Europa, muy escasamente se lee en los medios universitarios norteamericanos, y está bastante ausente del diálogo latinoamericano. Las razones de este aislamiento son complejas y, en parte, buena cuota de responsabilidad es también de los escritores. (Torres 8)

A pesar de su última afirmación, la escritora intenta esbozar algunas de las causas de tal situación: dejadez de los propios escritores venezolanos, rencillas personales entre

\footnotetext{
${ }^{8}$ Doña Inés contra el olvido ganó el Premio de Novela de la I Bienal Mariano Picón Salas (1991), realizada en Mérida (Venezuela). Con esa misma novela, la autora ganó en 1998 el Premio "Pegasus", otorgado por la Mobil Corporation. En este año, otra novela de Torres, Los últimos espectadores del acorazado Potemkin quedó finalista del Premio de Novela "Rómulo Gallegos” de este año.
} 
ellos, que los llevaría a "sabotearse” el trabajo, la bien intencionada pero no siempre efectiva política editorial por parte del Estado. No menciona algo que parece más evidente: que esta idea del aislamiento nacional es una percepción que los propios escritores venezolanos alimentan y nutren. Ese sentirse no pertenecer a nada más sino a un país, sin conexiones aparentes con nada más en el mundo ha marcado gran parte de la propia reflexión sobre la literatura nacional.

\section{BiBLIOGRAFÍA}

Acosta Bello, Arnaldo. "Nuestras credenciales”. Tabla Redonda 4 (diciembre 1959): 4. Anónimo. “Testimonio”. Sardio 1 (mayo-junio 1958): 1-3 [Reproducido en: Santaella, 49-52].

“Las constantes de nuestra generación”. Sardio 5-6 (enero-abril 1959): 277-82 [Reproducido en: Santaella, 53-57].

Anónimo. "El gran magma”. Rayado sobre el techo de la ballena (21 de marzo 1961) [Reproducido en: Santaella, 62 y también Rama Antología 51].

Anónimo. “Homenaje a la cursilería”. Sardio 8 (mayo-junio 1961): 136 [Reproducido en: Rama Antología, 189].

Anónimo. “Premanifiesto”. Sardio 8 (mayo-junio 1961): 136-37 [Reproducido en: Rama Antología 49-50, bajo el título "Pareciera que todo intento de renovación”].

Anónimo. "Segundo manifiesto”. Rayado sobre el techo 2 (mayo 1963) [Reproducido en: Santaella, 63-65 y también Rama Antología 197-99].

Barrera Linares, Luis. "Diacronía textual de una narrativa sin rostro aparente". Iberoamericana 2/3 (78/79) (2000): 52-71.

Cadenas, Rafael. "Poesía, partido y realidad. 5 opiniones de Rafael Cadenas”. Tabla Redonda 5-6 (abril-mayo 1960): 2.

González León, Adriano. “¿Por qué la ballena?”. Rayado sobre el techo 3 (1964): 3-4 [Reproducido en: Santaella, 66-69 y también Rama, Antología 200-203].

Liscano, Juan. Tiempo desandado. Vol. I. Caracas: Ediciones del Ministerio de Educación, 1964.

Osorio, Nelson. La formación de la vanguardia literaria en Venezuela. Caracas: Academia Nacional de la Historia, 1985.

Rama, Ángel. “Salvador Garmendia y la narrativa informalista”. Ensayos sobre literatura venezolana. Caracas: Monte Ávila, 1990: 99-219 [Originalmente fue un libro cuyos datos son: Caracas, Ediciones de la Biblioteca de la Universidad Central, 1975].

Antología de El techo de la ballena. Caracas: Fundarte, 1987.

Sanoja Hernández, Jesús. “Notas para la 'burguesía intelectual””. Tabla Redonda 2 (junio 1959): $1-2$.

“Entre la loa y la destrucción”. Tabla Redonda 4 (diciembre 1959): 3.

“Novela”. Tabla Redonda 5-6 (abril-mayo 1960): 3-5.

Santaella, Juan Carlos. Diez manifiestos literarios venezolanos. Caracas: La Casa de Bello, 1986.

Sucre, Guillermo. “Sobre 'Tabla Redonda””. Papel Literario de El Nacional (04-061959): 3. 
“Alejo Carpentier: Guerra del tiempo”. Sardio 2 (julio-agosto 1958): 164-66. Torres, Ana Teresa. "De un cierto malestar en la literatura venezolana”. A beneficio de inventario. Caracas: Editorial Memorias de Altagracia, 2000: 7-11.

Vandorpe, Yasmine-Sigrid. "Los testimonios de Sardio". Revista Nacional de Cultura 292-293 (1994): 77-87. 